\title{
Recomendações e apontamentos para categorizações em pesquisas sobre redes interorganizacionais
}

\author{
Recommendations and notes for categorizations in research on interorganizational \\ networks
}

\author{
Julio Araujo Carneiro da Cunha ${ }^{1}$ \\ João Luiz Passador ${ }^{2}$ \\ Cláudia Souza Passador ${ }^{3}$
}

\section{Resumo}

Os estudos sobre redes interorganizacionais foram bastante explorados pela administração, principalmente, a partir da década de 1980. No entanto, ainda hoje, ocorrem embates sobre definições e metodologias nessa área. Isso faz com que pesquisadores fiquem frequentemente desamparados sobre a taxonomia desse objeto de estudo, o que dificulta a construção de uma base de conhecimentos estruturada. Por isso, o objetivo desta pesquisa é propor recomendações e apontamentos que auxiliem os pesquisadores a estabelecer elementos fundamentais para a categorização das redes interorganizacionais, auxiliando assim a identificá-las, para que possam ser analisadas, comparadas e compreendidas por suas características específicas. Para tal, o pesquisador pode categorizar a rede interorganizacional estudada baseando-se nos seguintes elementos: formação, tipos de alianças, orientação das relações, orientação do elo da cadeia, presença de uma organização central, governança, institucionalização, unidade de análise, tipo de competição, proximidade e necessidade de sinergias das alianças. No entanto, a categorização é apenas um dos passos do conjunto de ações a serem realizadas no processo de pesquisa sobre redes interorganizacionais. Como possível alternativa para um processo empírico abrangente, recomenda-se: (1) estabelecer claramente um objetivo de pesquisa sobre redes interorganizacionais; (2) limitar a rede conforme os objetivos da pesquisa; (3) escolher a estratégia de pesquisa mais adequada ao objetivo de estudo; (4) atentar para quais os pontos focais da pesquisa e realizar seu estudo dentro de padrões éticos; (5) compreender o contexto histórico-social da rede; (6) categorizar a rede; e (7) deixar claro no relatório final as categorizações estabelecidas e as justificativas das escolhas metodológicas.

Palavras-chave: Redes interorganizacionais. Metodologia. Categorizações de redes.

1 Doutor em Administração de Empresas pela Fundação Getulio Vargas / EAESP. Endereço: EAESP / FGV, Avenida Nove de Julho, 2029, Bela Vista, CEP 01313-902, São Paulo, SP, Brasil. E-mail: juliocunha@yahoo.com

2 Doutor em Administração de Empresas pela Fundação Getulio Vargas / EAESP; Professor doutor do Departamento de Administração da Universidade de São Paulo / FEA-RP. Endereço: Avenida dos Bandeirantes, 3900, Monte Alegre, CEP 14040-900, Ribeirão Preto, SP, Brasil. E-mail: jilpassador@usp.br

3 Doutora em Educação USP; Professora doutora do Departamento de Administração da Universidade de São Paulo / FEA-RP. Endereço: Avenida dos Bandeirantes, 3900, Monte Alegre, CEP 14040-900, Ribeirão Preto, SP, Brasil. E-mail: cspassador@usp.br 


\begin{abstract}
There have been many studies on interorganizational networks in the field of management since the 1980s. However, even nowadays there are still some disagreements concerning definitions and methods in this field of study. Researchers of this topic are frequently at a loss when it comes to its taxonomy, which hinders the construction of a structured knowledge base. Therefore, the objective of this study is to provide recommendations and notes for researchers in this field that may be helpful when it comes to establishing essential elements for the classification of interorganizational networks, enabling their identification in order to analyze, compare and understand them according to their specific characteristics. Therefore, a researcher can categorize his research object according to the following possibilities: formation; alliances types; guidance for relationships; guidance for links in the chain; presence of a central organization; governance; institutionalization; analysis unity; type of competition; proximity and; requirements for alliance synergies. However, categorization is just one of the steps to be taken by interorganizational researchers within a larger set of actions. As an alternative possibility for a broader empirical process, researchers are advised to: (1) Clearly establish an objective for inter-organizational network research; (2) Establish network boundaries according to research objectives; (3) Choose an adequate research strategy according to the established objective; (4) Be aware of what the focal points for the empirical research are and conclude the empirical study according to ethical standards; (5) Understand the historical and social context of the network; (6) Categorize the network; and (7) Point out the established categorizations and the justifications of the chosen methods in the final report.
\end{abstract}

Keywords: Interorganizational networks. Methodology. Network categorization.

\title{
Introdução
}

A discussão sobre as vantagens das alianças e dos relacionamentos tem origem nos estudos referentes às relações pessoais dos indivíduos. A ideia de que a diversidade de relações sociais pode trazer ganhos foi desenvolvida, principalmente, no terceiro quartel do século passado, com destaque para os estudos de Simmel (1955) e de Granovetter (1973). Simmel (1955) identificou como o indivíduo se afiliava a diversos grupos sociais (e.g. familiar, religioso) e também apontou pressões psicológicas pelo estabelecimento dessa variedade de afiliações, geradoras de uma multiplicidade de níveis de realidade em que esse indivíduo estava inserido. Por sua vez, Granovetter (1973) observou que uma rede de relacionamentos diversificada poderia ajudar o indivíduo a conseguir emprego. Percebia-se que a formação de alianças podia ser vantajosa, principalmente, pelo compartilhamento de recursos, sejam estes explícitos ou não.

Posteriormente, na década de 1970, esses estudos sobre alianças foram bastante explorados, com aplicação na sociologia do indivíduo. Nos anos 1980, a aplicação foi focada particularmente no campo da economia e das organizações (SMITH-DOER e POWELL, 2004). Assim, estudiosos direcionaram seus esforços para formular teorizações que embasassem a compreensão das redes da perspectiva das organizações. No entanto, as primeiras teorias elaboradas ainda eram insuficientes para suprir as necessidades da área. Por exemplo, a teorização de modelos híbridos entre diferentes concepções de não mercado e de não hierarquia proposta por Powell (1987) para teorizar as redes interorganizacionais demonstrou ser inviável, pois não foi possível abranger todos os tipos de redes e de colaboração entre organizações (POWELL, 1990).

Dessa forma, por mais que na década de 1980 os estudos sobre redes interorganizacionais tenham avançado, na década de 1990 deparou-se com a necessidade de conceitos e métodos que respaldassem os estudos da área (HALINEN e TÖRNROOS, 1998), pois havia discrepâncias entre as terminologias adotadas (NOHRIA, 1992). Para agravar a situação, os estudiosos do tema recorreram a outras teorias do contexto industrial para compreender o caso das redes, não havendo uma teoria específica e adequada aplicável a estas (SALANCIK, 1995; SYDOW e WINDELER, 1998). Essa falta de definições gerou problemas de efetividade de teorias para o entendimento das redes interorganizacionais, já que estas tinham suas especificidades negligenciadas quando observadas pela ótica de uma linha de pensamento inadequada (CARNEIRO DA CUNHA, 2008). 
Atrelado a isso, a inexistência de teorias consistentes e adequadas prejudica não somente a construção conceitual do campo, mas também as práticas gerenciais (GHOSHAL, 2005).

Concomitantemente, Oliver e Ebers (1998) realizaram uma meta-análise com os artigos publicados sobre redes interorganizacionais de 1980 a 1996, identificando a mesma situação, na qual conceitos, teorias e resultados empíricos heterogêneos apresentados ao longo dos estudos culminaram numa desorganização da arena de discussões sobre o tema. Esses resultados foram corroborados no Brasil por meta-análises realizadas sobre estudos nacionais relacionados ao tema (ALVES, PEREIRA e BAZZO, 2010; BALESTRIN, VERSCHOORE e REYES JUNIOR, 2010; CUNHA e CARRIERI, 2003; VIZEU, 2003), identificando-se que o campo de pesquisa é heterogêneo do ponto de vista teórico.

Além dessas diferenças de suporte teórico, foram muitos os métodos adotados nos estudos sobre redes interorganizacionais, de forma que esses dois fatores, juntos, acarretaram uma diversidade de resultados e de conclusões para as pesquisas da área, gerando problemas para integrar e comparar os estudos realizados (RITTER e GEMÜNDEN, 2003). Diante dessa dificuldade, torna-se iminente a necessidade de teorias e métodos capazes de colocar os resultados de forma cumulativa num mesmo plano. Ademais, percebe-se como necessária a interação das conclusões levantadas nos estudos da área, no intuito de se desenvolver, de forma mais eficiente, a construção e a acumulação de conhecimentos. É preciso elaborar teorias e métodos sobre redes interorganizacionais válidas empiricamente capazes de suprir essa deficiência.

Nos dias de hoje, ainda que algumas diretivas já tenham sido estabelecidas a fim de se propor elementos importantes para a pesquisa empírica de estudos de casos de redes interorganizacionais (e.g. HALINEN e TÖRNROOS, 2005), ainda existe a carência de definições e de teorizações amplamente aceitas na comunidade acadêmica no que tange à taxonomia dessas redes. Isso implica que por mais que se tenha avançado no campo de estudo das redes interorganizacionais, no sentido de entender de que forma elas se estruturam e como operam (e.g. AGRANOFF e McGUIRE, 1999; GRANDORI e SODA, 1995; PODOLNY e PAGE, 1998; PROVAN, FISH e SYDOW, 2007; THORELLI, 1986) e de desenvolver algumas tipologias (e.g. BORGATTI e FOSTER, 2003; CORREAA, 1999; GRANDORI e SODA, 1995; ROWLEY, 1997; TODEVA e KNOKE, 2005; UZZI, 1997; PRENKERT e HALLÉN, 2006; WHETTEN, 1981), ainda perdura o problema da falta de padronização na conceituação, teorização e metodologia da área. Comumente, as definições conceituais ainda são confundidas, quando não misturadas, e teorias aplicáveis a diferentes contextos industriais são transpostas ao contexto das redes interorganizacionais sem a devida adaptação.

Portanto, faltam aparatos teóricos, conceituais e categóricos para a compreensão dos fenômenos relacionados às redes interorganizacionais. Sem essa sustentação teórica, não há um pleno entendimento das organizações em rede. Nesse cenário, a teorização e a categorização adequada sobre as redes interorganizacionais poderiam ser uma maneira de se estabelecer um arcabouço de experiências e teorias válidas empiricamente, $o$ que auxiliaria os gestores de organizações consorciadas a tomar decisões de maior previsibilidade e eficácia. Isso é importante porque são necessárias práticas de gestão específicas para as redes (YOSHINO e RANGAN, 1995), respeitadas as especificidades de cada uma delas. É vantajoso para as organizações trabalharem de forma cooperada (CONTRACTOR e LORANGE, 2002; DYER e SINGH, 1998; PRAHALAD e RAMASWAMY, 2004; SMITH, CARROLL e ASHFORD, 1995; WILLIAMS, 2005; ZAHEER e BELL, 2005), o que, entretanto, não é aproveitado, pois grande parte dessas iniciativas de interação não consegue tirar pleno proveito das vantagens ou, ao menos, não consegue atingir seus objetivos propostos (e.g. ARIÑO e DE LA TORRE, 1998; DACIN, HITT e LEVITAS, 1997; HARRIGAN, 1988; HOLLOWAY, 2009; MILES e SNOW, 1992). Dessa forma, o problema poderia ser minimizado se teorias adequadas dando sustentação às práticas fossem desenvolvidas, o que aconteceria mais efetivamente se o campo de pesquisa sobre o tema estivesse integrado e organizado.

Uma vez contextualizada a área de estudos sobre redes interorganizacionais, o intuito deste artigo é, portanto, auxiliar nas pesquisas e reflexões desse campo de pesquisa. Assim, o objetivo aqui não é apenas estabelecer recomendações sobre para quais etapas fundamentais de pesquisa quem estuda as redes 
interorganizacionais deve estar atento, mas também apresentar apontamentos sobre quais categorias esse estudioso pode definir para uma pesquisa mais efetiva sobre os fenômenos desse campo de estudo.

Para atender a esse objetivo proposto, o método de pesquisa escolhido foi a revisão bibliográfica. Isso porque a síntese de pesquisas realizadas nas ciências sociais pode ser uma forma de levantar aquilo que foi estudado sobre o tema de interesse, conforme critérios de pesquisa estabelecidos pelo pesquisador (COOPER, 1998). Por meio dessa estratégia de pesquisa, foi construído um arcabouço teórico, consolidando-se pontos da revisão de literatura que os autores deste estudo julgaram mais relevantes e capazes de embasar os principais elementos para a categorização das redes interorganizacionais.

\section{Alianças e Redes Interorganizacionais: Nós e Elos}

Para entender as redes interorganizações, uma boa estratégia é compreendê-las de forma sistemática por meio das conceituações de nós e elos. Nós são os pontos da rede, ou seja, os agentes constituintes dela, enquanto os elos são as ligações entre esses nós. Segundo Marteleto e Silva (2004, p.41): “As redes são sistemas compostos por 'nós' e conexões entre eles que, nas ciências sociais, são representados por sujeitos sociais (indivíduos, grupos, organizações etc.) conectados por algum tipo de relação". Assim, numa perspectiva organizacional, os nós seriam as organizações e os elos, as relações entre essas organizações.

As ligações entre os nós podem variar em duas dimensões; isto é, pode-se observar entre quais nós se realizam as ligações e também a densidade das relações sociais. A primeira dimensão se diferencia em dois tipos de ligações: uma refere-se às relações com organizações do mesmo setor ou com nós de uma indústria diferente; a outra parte do pressuposto de que existem ligações que podem ser mais fortes do que outras. Granovetter (1985) categoriza essas ligações em dois tipos: as ligações fortes, que são aquelas ligadas às relações de maior proximidade, e as ligações fracas, que são aquelas que representam ligações existentes, mas, sem tanta proximidade. Narayan (2002) corrobora as ideias de Granovetter (1985) oferecendo outra classificação, na qual as relações sociais podem ser do tipo "ponte", mais frágeis por sua menor proximidade institucional e que caracterizariam as redes heterogêneas, e do tipo "cola", mais próximas e capazes de dividir valores e normas comuns (institucionalizações informais) entre os nós.

De acordo com Whetten (1981), as relações entre organizações das redes podem ocorrer de quatro formas: (1) pares, quando existe uma relação simples de mútua colaboração entre dois nós; (2) conjunto de relações, que representa a soma das relações entre pares; (3) conjunto de ações, quando as relações existentes respeitam um funcionamento para se atingir um propósito estabelecido; (4) rede, quando o conjunto de todas essas relações anteriores é visto de forma macro. Entretanto, a definição de Whetten (1981) pode ser contestada, conforme alguns contextos específicos, ou, ainda, substituída pela ideia de constelações de organizações (DAS e TENG, 2002), segundo a qual o conjunto de alianças estratégicas estabelece uma relação competitiva entre organizações e grupos. Deve ser observado que é importante levantar essa discussão para que se compreenda que as relações entre organizações, num âmbito maior, podem ser caracterizadas como rede, conjunto de ações e relações, constelações etc. Diante disso, cabe ao pesquisador escolher qual conceituação é mais adequada ao que ele pretende estudar. O importante nesse momento é que o pesquisador entenda que a rede é formada por todo o tecido de relações entre organizações.

Nessa perspectiva conceitual de rede, as firmas podem se organizar de diversas formas operacionais e de acordo com vários objetivos. Para Todeva e Knoke (2005), esses formatos são: relações hierárquicas, joint ventures, união para investimentos de capitais, cooperativas, consórcios de pesquisa e desenvolvimento, acordos de cooperação estratégica, cartéis, franquias, licenças, redes subcontratantes, grupos de padronização industrial, grupos de ação (para lobbies e influência política) e relações de mercado. Com essa diversidade de inter-relações, é importante que o pesquisador identifique o tipo de rede com a qual está lidando. 


\section{Iniciando a Pesquisa sobre Redes Interorganizacionais}

\section{Definindo o objetivo da pesquisa}

Uma vez compreendido como pode ocorrer a relação entre os nós de uma rede e adotada uma conceituação para essa rede, o pesquisador, apoiado na sua epistemologia de estudo, estabelece a pergunta de pesquisa que pretende responder na sua investigação sobre redes interorganizacionais. A sugestão é que essa pergunta seja capaz de identificar um gap existente no campo de estudo que torna a pesquisa relevante para a área. Assim, munido de uma pergunta de pesquisa, o pesquisador pode definir um objetivo para seu estudo. Somente então o pesquisador é capaz de estabelecer parâmetros para a escolha de qual rede quer estudar e de quais fenômenos dessa rede vai abordar na sua pesquisa. Entretanto, nem sempre ele consegue ter acesso à rede que idealizou para sua pesquisa, vendo-se forçado a escolher, muitas vezes, uma rede na qual ele consegue ter o acesso de campo. Nesse caso, nada impede que o pesquisador volte atrás e reajuste seu objetivo, adequando-o às melhores oportunidades que o(s) caso(s) que ele tem em mãos pode $(\mathrm{m})$ lhe oferecer. Após essa definição de quais serão os casos analisados, o passo seguinte é estabelecer os limites exatos da rede interorganizacional.

\section{Estabelecendo os limites da rede interorganizacional abordada}

Estabelecer esses limites da rede abordada não é uma tarefa fácil (HALINEN e TÖRNROOS, 2005) porque a ideia é que eles sejam estabelecidos de forma a abranger os interesses de pesquisa propostos. Principalmente, quando o pesquisador entende que muitas alianças entre organizações só podem ser compreendidas dentro de um contexto maior - isto é, como parte integrante de uma teia de relacionamentos que envolve diversas outras alianças (DOZ e HAMEL, 2000) - e que a formação de redes é um processo intrínseco ao movimento de globalização (CASTELLS, 1999). Assim, considerando que as ligações entre organizações, na grande maioria das vezes, fazem parte de uma rede de relacionamentos maior, cujos limites podem ser bastante expansivos, surge um problema para o pesquisador: se ele abstrair as relações num âmbito global, tentando identificar até onde cada aliança pode chegar para limitar a rede que vai pesquisar, ele pode encontrar sérias dificuldades de mapeamento, num trabalho que lhe custaria um esforço descomunal e tomaria um tempo que ultrapassa qualquer prazo de pesquisas.

Não obstante, internamente, a rede pode também criar sub-redes que têm sua própria autonomia. De acordo com Powell et al. (2005), conforme as organizações se desenvolvem nas suas atividades colaborativas, é comum que diversifiquem suas conexões na rede para outras formas coesas de relações (sub-redes) que têm suas múltiplas ligações independentes. Quanto mais diversificada for a constituição da rede, mais ligações e elos ela desenvolve, mais complexas são suas relações e maiores são as chances de sobrevivência dela perante contingências. Em outras palavras, a rede se fortalece quando há uma estrutura mais heterogênea, com diferentes tipos de atores, o que a torna, cada vez mais, autossuficiente, sem depender de outras redes. Portanto, há complexidades envolvendo as inter-relações que exigem do pesquisador impor limites para viabilizar sua pesquisa acadêmica, seja expandindo a visão da rede, reduzindo-a para suas sub-redes ou descartando essas sub-redes.

Desse modo, é de suma importância que o pesquisador seja capaz de delimitar a rede que pretende estudar. Para facilitar seu trabalho, recomenda-se, se possível, mapear graficamente a rede. Existe, inclusive, uma série de softwares (com destaque para os mais populares: UCINet, Pajek, ORA, statenet - pacote pertencente ao ambiente R, GUESS, iPoint e NetMiner) que podem auxiliar no mapeamento das redes sociais. Posteriormente, esses programas ainda podem ser úteis na pesquisa, no que tange aos cálculos estatísticos relacionados com as relações, centralidade dos nós etc. 
Nesse processo de identificação das ligações relevantes ao seu objetivo de estudo, o pesquisador poderia buscar responder a algumas questões, como: A que fenômeno as ligações que eu vou estudar devem estar diretamente relacionadas? Quem são os agentes (nós) que estão ligados ao fenômeno específico que eu quero estudar? Quais as atividades contidas dentro do meu escopo de pesquisa e quais nós (organizações) estão dentro desse escopo? Existe uma organização (nó) central da qual emergem as demais relações (elos)? Que critérios devo usar para delimitar a participação ou não dos nós na rede estudada?

\section{A escolha da estratégia de pesquisa}

Alguns esforços já foram feitos na tentativa de se identificar estratégias de pesquisa para as redes interorganizacionais. Fombrun (1982), por exemplo, já defendia haver três estratégias adequadas para esse tipo de estudo: (a) nodais - decomposição da rede nos componentes nodais (nós), com foco na rede, conforme a visão dos nós; (b) diádicas - decomposição da rede em partes nodais, com ênfase nas relações entre as partes; (c) triáticas - todas as possibilidades de tríades na rede, com foco na composição dessas tríades em termos de relações ligando os três nós.

No entanto, por mais que o trabalho de Fombrun (1982) tivesse seus méritos em levantar a discussão sobre estratégias para a pesquisa aplicada especificamente sobre redes interorganizacionais, seu esforço não foi capaz de suprir todas as necessidades dos pesquisadores da área. Além do direcional sobre a perspectiva a ser adotada nos estudos sobre as redes interorganizacionais, é importante que o pesquisador escolha uma estratégia metodológica adequada.

É igualmente importante que o pesquisador consiga uma sintonia entre a estratégia de coleta de dados do campo e seus propósitos de pesquisa, para que essa escolha metodológica seja congruente com seus objetivos previamente estabelecidos. Ele também precisa buscar coerência entre o método escolhido e sua pergunta de pesquisa (MAXWELL, 2005). Para essa escolha, o pesquisador pode partir da premissa de que a opção pelo método a ser utilizado numa pesquisa científica requer uma noção inicial da realidade a ser estudada, de modo a caracterizar como o fenômeno ocorre e qual a abordagem mais adequada para se compreender o fenômeno a ser estudado (MORGAN, 1983). Portanto, não cabe aqui definir se o estudo de caso, o uso de questionários, o grupo focal ou a etnografia são estratégias ideais para a pesquisa sobre redes interorganizacionais. As demandas do pesquisador, as especificidades da situação e as condições de acesso oferecidas pela rede é que vão definir qual a estratégia a ser adotada. Pode-se até tecer recomendações sobre como executar cada uma dessas estratégias de pesquisa, mas não há como definir uma regra geral aplicável a todos os estudos do tema.

Pontos Importantes para a Coleta de Dados do Campo

\section{Informantes-chave das redes}

Para a coleta de dados empíricos de uma rede interorganizacional, o pesquisador precisa ter acesso a fontes de informação que lhe ofereçam o que ele necessita para sua pesquisa, levando em conta seu foco e seus objetivos. Por isso, primeiro de tudo, é desejável que esse pesquisador tenha claro se sua unidade de análise é o indivíduo, a organização ou a própria, para saber se o respondente é capaz de oferecer as informações dele esperadas. Por exemplo, se o pesquisador quer entender como funcionam os relacionamentos da organização, ele deve procurar um respondente que conheça esses relacionamentos, que tenha uma visão macro da rede na qual a organização está inserida e não alguém que entenda somente dos processos internos da organização. 
Alguns estudiosos da área alegam que para entender a rede interorganizacional é importante que o pesquisador conte com o máximo de respondentes possível, de modo que obtenha informações de diferentes perspectivas. Para Taylor (2005), uma boa estratégia para entender a rede é buscar um informante em cada uma das organizações participantes. No entanto, essa recomendação deve ser analisada com cuidado porque a identificação de informantes-chave varia caso a caso, conforme cada rede esteja estruturada. Por exemplo, em relação a uma rede que tenha uma organização central, é importante usar essa organização como fonte de informações. No caso de uma rede oriunda de iniciativas de união propostas por um agente intermediário, é importante entrevistar uma figura-chave desse intermediário para se compreender a rede como um todo. Portanto, alguns respondentes devem ser fundamentais para a compreensão do funcionamento da rede, de acordo com o objetivo estabelecido pelo pesquisador.

Por outro lado, segundo Kumar, Stern e Anderson (1993), recorrer a informantes-chave nas redes interorganizacionais pode ser conflitante porque contar com múltiplos respondentes pode levar a respostas divergentes, o que não significa que uma resposta seja falsa em comparação com outra, mas que todas podem ser verdadeiras. Os autores alegam que para contornar esse problema, o pesquisador pode adotar um procedimento que combine seus relatórios dentro de um conceito organizacional. Para tal, existem três métodos: o de agregação, o de consenso e a modelagem de traços pessoais latentes, sem contar, ainda, com um modelo híbrido que abrange essas três metodologias.

\section{Ética na pesquisa}

É importante também que a abordagem e o relatório de pesquisa sigam padrões éticos; até mesmo para garantir que o pesquisador consiga coletar dados empíricos válidos e condizentes com a realidade da rede estudada (BORGATTI e MOLINA, 2003). Se, com base nos dados que levantou, tomar decisões gerenciais pouco éticas, o pesquisador pode acabar perdendo a confiança de potenciais fontes de informação, o que traria prejuízos tanto para acadêmicos quanto para práticos da área. Por exemplo, ao analisar uma rede interorganizacional em que seus membros competem entre si, não se recomenda que um pesquisador divulgue informações de um concorrente ao outro. Tampouco se sugere identificar especificamente algum respondente em seu relatório final, quando houver análise de resultados consolidados. Isso pode prejudicar suas futuras pesquisas e acompanhamento da rede.

\section{Contexto Histórico-social das Redes Interorganizacionais}

As relações entre organizações, especialmente, as econômicas são marcadas pela realidade social onde estão inseridas (GRANOVETTER, 1985), de forma que os mercados de negócios são socialmente construídos numa determinada realidade social (HEDDA e TÖRNROOS, 2008). Seguindo esse pensamento, as redes interorganizacionais detêm elementos sociais de seu ambiente que influenciam as organizações participantes a se comportarem e a tomarem decisão dentro dos valores socialmente estabelecidos. Pode, inclusive, ocorrer o fenômeno do isomorfismo (DIMAGGIO e POWELL, 1983), em que as organizações participantes imitam o ambiente social da rede (ORDANINI, RUBERA e DEFILLIPPI, 2008).

Por essas razões, é aceito que as redes influenciam profundamente a conduta e o desempenho das organizações participantes (GULATI, NOHRIA e ZAHEER, 2000). Daí surge o termo "embeddedness" (GRANOVETTER, 1985) aplicado às redes interorganizacionais (e.g. GULATI, 1998; HALINEN e TÖRNROOS, 1998; POWELL, 1990) ou, numa tradução para o português, a "imersão social" (BALDI e VIEIRA, 2006). Isso quer dizer que toda a rede interorganizacional está inserida num contexto social, principalmente, quando está espacialmente concentrada num mesmo local, sendo assim influenciada pelo seu desenvolvimento histórico-social. As características sociais desse ambiente são, portanto, decisivas para 
definir as características da rede interorganizacional. Essa imersão social pode ser positiva no que se refere à economia de tempo, à integração de acordos, às melhorias de eficiência e adaptação entre as organizações (UZZI, 1997). Por outro lado, pode também trazer restrições sociais de comportamento para as organizações participantes (BRASS et al, 2004).

Essas considerações levam a crer que o histórico das organizações e da rede tem influência no que elas são hoje, além de apontar perspectivas. A análise das relações interorganizacionais está ligada a uma análise longitudinal, desde sua criação, passando por seu desenvolvimento, até seu término (RING e VAN DE VEM, 1994). Em sua formação, as novas redes carregam ranços de experiências passadas de seus participantes, ao mesmo tempo em que criam expectativas quanto ao futuro (TÖRNROOS, 2004). Isto é, a existência prévia de relacionamentos pode determinar a impossibilidade da formação de novas redes pela saturação das relações ou, então, pode estimular a formação de novas alianças pela experiência prévia de bons relacionamentos (GULATI, 1995). Assim, eventos conectados às redes podem servir como forma para que o pesquisador desenvolva teorias, métodos e modelos sobre o fenômeno das redes interorganizacionais (HEDAA e TÖRNROOS, 2008).

De fato, alguns estudos sobre redes vêm se caracterizando por apresentar o histórico da rede no intuito de prover subsídios para a sua compreensão (e.g. FORREST, 2003; TODEVA, 2007; YEUNG, 1997). Por exemplo, uma região onde existe uma grande empresa especialista em determinado setor tem grandes perspectivas, não apenas de formar uma base de conhecimentos específicos daquela indústria, mas também de gerar uma rede especializada através das demais empresas que chegam à região para dar suporte as suas atividades. Se essa grande organização sair de lá, existe ainda assim uma base de conhecimentos instalada na região, proveniente dos ex-funcionários e das demais empresas, que pode impulsionar a formação de uma rede de pequenas empresas que realizem atividades semelhantes àquelas existentes quando a grande empresa estava lá.

Outros exemplos de efeitos que um ambiente de rede pode gerar são os fenômenos de: spill-over (e.g. OWEN-SMITH e POWELL, 2004), que é quando uma organização geradora de inovação tem seus conhecimentos "transbordados" para a rede, gerando um ambiente detentor daquele conhecimento específico, e spin-off (e.g. CHESBROUGH e ROSENBLOOM, 2002), que ocorre quando uma organização surge em detrimento da experiência adquirida em outra, explorando os conhecimentos. São casos em que o histórico da rede gera sinergias para formação de novas organizações, podendo impulsionar a participação dessas novas organizações na rede existente ou na formação de uma nova.

Para Halinen e Törnroos (2005), os acontecimentos históricos são fundamentais para a análise do contexto no qual a rede está inserida. Esse contexto, para os autores, está ligado aos diversos níveis de imersão social da rede (e.g. unidade de negócios, organização, indústria, região). Ainda segundo Halinen e Tömroos (2005), em cada nível desses, o desenvolvimento da rede é dependente do passado, o qual se reflete no presente que por sua vez está conectado ao futuro.

A figura a seguir sintetiza graficamente a ideia dos autores, abrangendo a perspectiva temporal de análise das redes interorganizacionais. 
Figura 1

Estrutura geral para análise de redes interorganizacionais

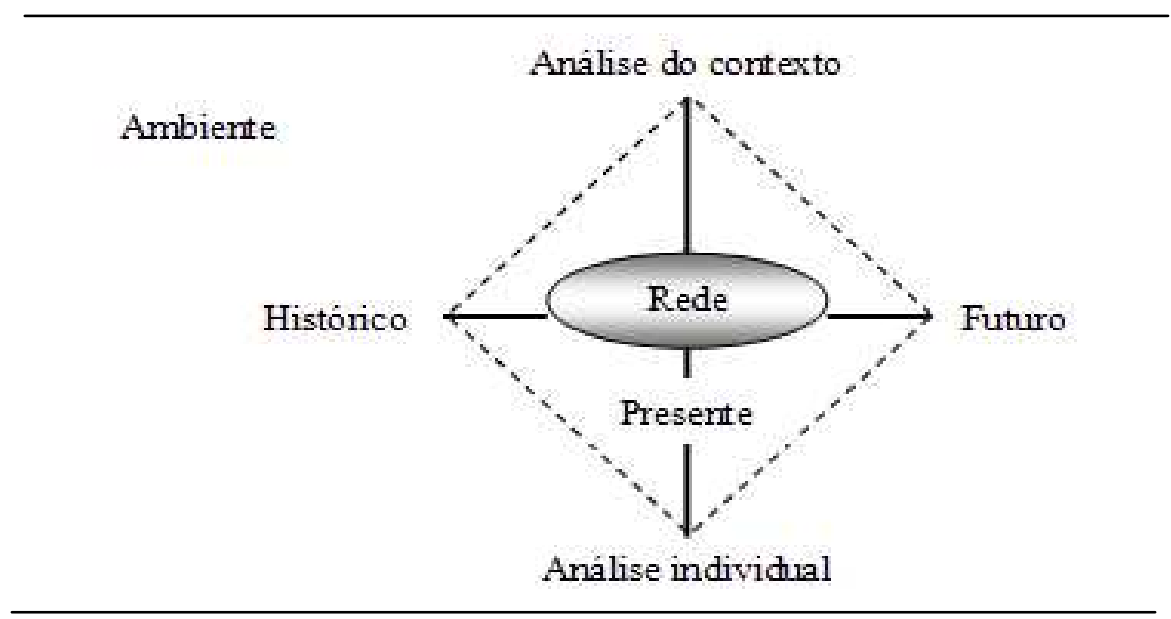

Fonte: Halinen e Törnroos (2005, p.1290).

\section{Tipologias de Redes Interorganizacionais}

Depois de compreendido o contexto histórico-social no qual a rede está inserida, uma alternativa para suprir a necessidade de identificação e classificação da rede é categorizá-la. Essas categorias podem ser preestabelecidas ou, como propõe Strauss (1987), abstraídas do campo numa pesquisa qualitativa. Este levantamento teórico propõe algumas categorias predefinidas pela literatura existente, as quais os autores consideraram as mais relevantes.

\section{Formação}

Como mencionado anteriormente, antecedentes relativos ao contexto histórico das organizações podem resultar numa propensão à formação de redes. Assim, existe a influência social e ambiental que pode estimular a formação das redes. Por sua vez, essa influência pode gerar afinidades entre as organizações que estimulam a associação voluntária entre elas. Para Oliver (1990), o estimulo às relações interorganizacionais depende de seis elementos: necessidade de agregação; assimetria no controle para manutenção do poder naquela indústria; reciprocidade para cooperação e estabelecimento de objetivos comuns; eficiência recíproca (principalmente, em termos de custos); estabilidade e, portanto, previsibilidade; além da legitimidade perante as normas do ambiente. Esses são elementos que geram afinidade entre as organizações para elas se associarem e que, portanto, acabam estimulando a aproximação entre elas.

Por outro lado, algumas redes podem ser desenvolvidas através de programas realizados por intermediários, geralmente, agentes de desenvolvimento, como, por exemplo, a Federação das Indústrias do Estado de São Paulo (Fiesp), o Serviço Brasileiro de Apoio às Micro e Pequenas Empresas (Sebrae) e secretarias municipais, entre outros. Na grande maioria das vezes, esses agentes indutores de relações têm interesses no aspecto desenvolvimentista dos participantes e da região (HASTENREITER FILHO, 2005). A efetividade da participação desses agentes para a formação de redes interorganizacionais é algo em discussão, havendo uma divergência de linhas de pensamento, em que por um lado se defende que eles são propulsores de relações 
(HASTENREITER FILHO, 2005) e por outro, que eles podem despertar receio nos participantes (TELLES, 2002). No entanto, entender a presença de um intermediário é fundamental para se conhecer o funcionamento da rede, seus objetivos e tipos de relações, tal como os interesses sociais, econômicos e políticos existentes por trás da formação da rede.

\section{Tipo de aliança}

As alianças entre organizações podem ser de dois tipos: vertical e horizontal. As alianças horizontais são aquelas que ligam empresas da mesma indústria, ou seja, que competem no mesmo mercado (SILVERMAN e BAUM, 2002). São empresas do mesmo nível dentro da cadeia, portanto. Em alianças horizontais, conceitos tradicionais de competição e hierarquia passam a não fazer sentido, dado que se têm novas relações, principalmente, em termos de colaboração e comunicação (POWELL, 1990). Nesse caso, as organizações podem ser observadas a partir do foco na cooperação entre elas.

De forma análoga, as alianças verticais são aquelas entre organizações de diferentes níveis da cadeia, isto é, entre organizações com diferentes funções dentro do processo produtivo (DYER, 1997). Essa relação de diferentes níveis da cadeia produtiva pode estar relacionada com o fornecedor ou o cliente da organização (HARRIGAN, 1988) dentro da perspectiva de rede dela. Lorange e Roos (1996) afirmam que quanto maior o grau de interdependência das relações entre organizações, maior o grau de integração vertical dessas relações. É importante ressaltar que, dentro da rede, uma organização pode atuar por meio de alianças horizontais, ao mesmo tempo em que coexistem outras relações suas de alianças verticais (MESQUITA e LAZZARINI, 2008).

\section{Orientação das relações}

Por mais que na administração o estudo de redes interorganizacionais esteja muitas vezes apoiado na lógica de mercado, é importante ter em mente que a formação de redes interorganizacionais não está ligada necessariamente a ganhos financeiros. Passador (2003, p. 5) afirma que: "rede de empresas consiste em um tipo de agrupamento de empresas cujo objetivo principal é fortalecer as atividades de cada um dos participantes da rede, sem que, necessariamente, tenham laços financeiros entre si”. Por isso, redes podem ter uma orientação puramente mercadológica e podem ainda trazer ranços de ligações sociais, que por vezes se sobrepõem aos interesses financeiros. Diante disso, Austin, Stevenson e Wei-Skillern (2006) diziam poder haver duas naturezas distintas para o estabelecimento das redes interorganizacionais: a orientação para fins comerciais e a orientação para fins sociais. A orientação de formato competitivo tem como principal finalidade os ganhos financeiros e a competição de mercado (PORTER, 1998) na ótica funcionalista e utilitarista proveniente da visão gerencialista norte-americana. O segundo caso se preocupa prioritariamente com a formação do capital social (INOJOSA, 1999) e com as relações de cultura, confiança, solidariedade, altruísmo etc.

No Brasil especificamente, duas meta-análises (CUNHA e CARRIERI, 2003; VIZEU, 2003) verificaram que a corrente teórica utilizada, em sua maioria, era a técnico-econômica, de influência norte-americana. Porém, com o aumento da relevância das pesquisas de cunho social Brasil, a corrente fenomenológica não funcionalista embasada no capital social e na análise histórico-cultural tornou-se uma corrente de pensamento crescente (BEGNIS, PEDROZO e ESTIVALETE, 2005).

Diante desse embate, o que se percebe é que as redes interorganizacionais são um fenômeno que envolve diversas correntes teóricas e que identificam diversas conceituações setoriais para as redes (COZER, PÓLO e CAMPOMAR, 2009), o que faz esses estudos demandarem uma abordagem multidisciplinar (PASSADOR e 
CARNEIRO DA CUNHA, 2008). Entretanto, apesar disso ser o recomendável, cabe ao pesquisador ter claro quais os objetivos de pesquisa estabelecidos para definir se é possível estabelecer um modelo híbrido de análise não conflitante ou se ele realiza um estudo seguindo uma orientação específica. Nesse sentido, cabe lembrar que uma orientação específica pode representar uma limitação de seu estudo.

\section{Orientação do elo da cadeia}

Para Canina, Enz e Harrison (2005), é importante que o pesquisador perceba se a formação da rede tem caráter de atendimento à demanda ou se ela existe por questões relativas aos aspectos produtivos dos seus participantes. Corroborando isso, Gereffi (1999) diz que em termos econômicos, existem dois tipos de redes desenvolvidas: aquelas dirigidas pelos produtores e aquelas dirigidas pelos compradores. Dessa forma, quando a rede analisada pelo pesquisador for definida como de orientação competitiva (econômica), resta saber ainda se ela é dirigida pelos aspectos produtivos ou varejistas. Isso quer dizer que as alianças e ligações entre organizações podem ocorrer visando ao escopo comercial, como podem ocorrer com orientação para o processo produtivo. Utilizando como exemplo dois casos de redes localizadas geograficamente num mesmo local, temos o caso dos shopping centers, em que existe um conglomerado de organizações varejistas com finalidade comercial. Outro exemplo são os clusters, como o de produtos eletrônicos no Vale do Silício (na Califórnia, EUA), em que as organizações são concentradas no local voltadas para o processo produtivo de equipamentos eletrônicos.

\section{Presença de uma organização central}

A organização central é o principal nó da rede, sendo aquela com poder de estimular as relações da rede e a mais influente. No entanto, a presença dessa organização central pode ser uma ameaça, quando concorrente, ou um fortalecedor, quando coordena e tem influência essencial na rede vertical. Por exemplo, um grande parceiro numa aliança vertical pode representar um grande fornecedor ou um grande comprador, o que estimula as alianças com ele. Num outro caso de fortalecimento, aliar-se a uma grande empresa pode ser uma forma estratégica de concorrer com os líderes da indústria. Por outro lado, a presença dessa organização central pode ser uma ameaça em termos de concorrência. Por exemplo, numa rede focada no comprador, a presença de um grande concorrente pode ser prejudicial para a manutenção das demais organizações no mercado. A organização central pode ter maior poder de competitividade ante os demais membros da rede, podendo prejudicá-los ao invés de fortalecê-los, principalmente, quando essa organização central se identifica como concorrente dos demais membros.

\section{Governança}

A natureza da governança das redes interorganizacionais pode definir os padrões de institucionalização da rede, de forma a controlar e alinhar as ações das organizações participantes (PARK, 1996). A governança de uma rede está relacionada à sua coordenação, que pode se dar na forma de sistemas sociais orgânicos (informais) ou na de estruturas burocráticas entre as organizações, com relações contratuais entre elas (JONES, HESTERLY e BORGATTI, 1997).

Dessa forma, Provan e Kenis (2008) dizem que a rede de organizações pode ser governada conforme três modelos principais: (1) auto-organização, em que não existe a governança concentrada em um agente e as relações entre organizações ocorrem conforme a institucionalização social da rede; (2) presença de uma 
empresa-líder (chamada aqui de organização central) que coordena as ações entre as organizações participantes da rede e que, segundo Laumann e Pappi (1976), socialmente, detém poder e influência sobre os demais membros da rede; e (3) presença de uma entidade administrativa autônoma (denominada como intermediário neste estudo) que realiza a gestão de forma mais profissional e que é recomendável, de acordo com os autores, para as redes mais complexas.

\section{Grau de institucionalização}

O tipo de governança das redes interorganizacionais está diretamente ligado, portanto, ao seu nível de institucionalização. Entretanto, não é apenas com a governança que o grau de institucionalização está relacionado. Por exemplo, o nível de institucionalização está relacionado também com a orientação da rede. Isso ocorre porque redes com maior orientação social tendem a um menor grau de institucionalização, enquanto aquelas mais burocratizadas envolvem relações mais formais na intermediação dos interesses comerciais (GRANDORI e SODA, 1995). Por isso, é relevante entender se a rede estudada é regida por contratos formais e comerciais ou por relações informais entre organizações informais; neste caso, apontando para a possível existência de laços que superam as relações meramente comerciais. É importante ainda compreender que o nível de formalização das organizações atuantes em redes interorganizacionais pode trazer-lhes vantagens conforme o grau de institucionalização, ainda que também possa apresentar desvantagens (VLAAR, VAN DEN BOSCH e VOLBERDA, 2007). Por fim, o grau de institucionalização pode não ser visto de forma dicotômica, ou seja, pela existência ou inexistência de formalização de normas na rede, uma vez que pode haver uma gradação nesse nível de institucionalização (GAJDA, 2004).

\section{Unidade de análise}

Ao realizar uma pesquisa sobre redes interorganizacionais, uma das primeiras ações do pesquisador é definir qual a sua unidade de análise. A unidade de análise escolhida deve ser aquela que melhor responda à pergunta de estudo do pesquisador. Por isso, não existe uma unidade de análise correta para as pesquisas da área, mas sim aquela mais coerente com o objetivo de pesquisa estabelecido. Evan (1965) entendia que essa unidade de análise poderia ser tanto a organização quanto o conjunto de organizações formadoras da rede. Esse conceito pode ser encontrado também no pensamento de autores mais contemporâneos. Marsden (2005) é um exemplo, ao estabelecer que o foco de análise de estudo pode ser sobre um ator específico e sua atuação na rede ("egocentric") ou sobre toda a rede ("whole-network").

Entretanto, há correntes de pensamento sobre esse conceito que vão além, de forma que o pesquisador considera como nível de análise não somente os atores envolvidos com as redes, mas também os relacionamentos oriundos do fenômeno. Dessa forma, Pham (s/d) defende que em termos de atores, a análise pode abranger quatro perspectivas: (1) do indivíduo, analisando as influências da sistemática da rede intraorganizacional no trabalho rotineiro; (2) do grupo de indivíduos e suas atividades no contexto organizacional em rede; (3) da organização, pesquisando a gestão, a operacionalização e o papel da organização dentro de uma formatação organizacional específica; e (4) da rede, que se caracteriza pelo grupo de organizações e busca entender a coordenação, a gestão, o funcionamento e a operação da unidade supraorganizacional. $\mathrm{O}$ autor defende ainda que o nível de análise pode ter seu foco nas relações das organizações, que podem ser: (1) diádicas ou relação individual, entre duas organizações; (2) portfólio de relacionamentos, em que se foca um conjunto-chave de relações de uma organização ou rede; e (3) teia de relacionamentos, em que se considera toda a estrutura de relacionamentos delineada pela rede identificada pelo pesquisador. 
Dessa maneira, quando o pesquisador verificar uma rede pela perspectiva supraorganizacional, ele vai se deparar com o gerenciamento da rede, tal como o alinhamento entre os membros para se atingir um objetivo comum da rede (ZACCARELLI et al, 2008). Em algumas redes, a perspectiva supraempresarial é formalizada (e.g. gerenciamento de uma cadeia de suprimentos, administração de um shopping center), podendo ter a presença de um agente gestor. No entanto, em outros casos, as relações entre os nós da rede podem ter caráter implícito e não contar com uma figura gestora da rede para coordenar as ações (que acabam se coordenando por leis da economia). Por isso, é importante entender exatamente se o foco de estudo é o funcionamento da rede, da organização ou do indivíduo dentro da rede. O pesquisador precisa estar ciente dessas diferentes perspectivas de estudo.

\section{Tipo de competição}

Quando uma rede é classificada como orientada para o mercado (competitividade), a competição pode ocorrer em diferentes esferas. Ela pode ocorrer num nível supraorganizacional, entre redes, em vez de ocorrer entre organizações (GOMES-CASSERES, 1994). Cabe ao pesquisador entender se a rede em si tem concorrentes ou se apenas as organizações da rede competem entre si. Comumente, as redes de ligações verticais costumam competir com outras redes verticais. Por exemplo, em indústrias como a de vinhos, cuja rede está concentrada num mesmo local, e sendo essa região responsável direta pela caracterização do produto, os esforços para a competição podem ocorrer no nível das redes locais e não especificamente entre organizações.

Sobre a concorrência intrarrede, principalmente, envolvendo alianças horizontais, pode haver uma sistemática de funcionamento das redes que envolvem relações interligadas entre si e não meramente a ligação entre pares (entre competidores). Com isso, pode-se ter uma situação em que os ganhos provenientes da participação na rede compensam as perdas decorrentes de alianças com concorrentes. Por exemplo, durante a crise de 2008, as montadoras automotivas norte-americanas, mesmo sendo concorrentes no mercado, não tinham interesse que uma delas falisse, pois caso isso ocorresse, toda a rede ia ser afetada. Os fornecedores iriam enfrentar problemas de escala, e isso aumentaria os preços daquelas montadoras que permanecessem no mercado, diminuindo o poder competitivo das que suportassem a crise. São casos em que existe o chamado coopetition (BENGSTON e KOCK, 2000) quando, ao mesmo tempo em que as organizações atuam competitivamente, elas cooperam entre si. Nesses casos, a compreensão do funcionamento da competição associada com a cooperação na rede exige que o pesquisador busque estudar a realidade de forma única, considerando tanto os aspectos de complementaridade quanto os de compatibilidade capazes de sustentar esse tipo de relação (JARILLO, 1988).

\section{Proximidade}

A questão da proximidade das redes interorganizacionais pode também categorizar uma rede. A proximidade identifica o elo de semelhança que liga as empresas dentro de uma rede. Knoben e Oerlemans (2006) afirmam que os conceitos de proximidade podem dividir-se em três perspectivas:

(1) proximidade geográfica - em que a convivência numa mesma localidade pode gerar trocas de conhecimentos sociais e tácitos em maior magnitude, dado que existe maior socialização entre os membros da rede (CARNEIRO DA CUNHA, 2006);

(2) proximidade organizacional - ligada às organizações que detêm mindsets e comportamentos semelhantes, usando os mesmos sistemas de representações e crenças (TORRE e RALLET, 2005). Para Knoben e Oerlemans (2006), a proximidade organizacional engloba aspectos de 
proximidade cultural, cognitiva, social e institucional entre as organizações. Nessa mesma linha, as parcerias podem ocorrer entre organizações do mesmo setor ou entre organizações de diferentes setores da economia, observando que as parcerias com empresas de um mesmo setor tendem a apresentar maior proximidade organizacional; e

(3) proximidade tecnológica - diz respeito à base de conhecimentos tecnológicos das organizações, em que os níveis mais elevados de conhecimento geram uma maior sofisticação de linguagem e comunicação. Uma relação entre organizações com diferentes níveis de tecnologia e conhecimento pode trazer vantagens e desvantagens. Por um lado, bases diferentes de habilidades entre organizações favorecem que nos diferentes extremos de mindsets, novos conhecimentos e inovações surjam em decorrência da maior exposição às experiências pelas quais essas organizações passam (POWELL e GRODAL, 2005); por outro lado, diferentes estruturas cognitivas podem criar barreiras a uma comunicação fluída entre as organizações (GRANT, 1996).

\section{Necessidades e sinergias das alianças}

É importante entender que as alianças entre organizações geram trocas entre elas e que essas trocas não trazem ganhos isolados, mas de elementos que, juntos, geram ganhos sinérgicos para as organizações aliadas (NIELSEN, 2005). Esses ganhos podem ser tanto de caráter tangível quanto intangível (GOMESCASSERES, 1997). Isto é, além dos ganhos tradicionais de custos, especialmente, dos custos de transação (WILLIAMSON, 1979), os elementos sociais e culturais, por exemplo, podem ser ganhos intangíveis decorrentes da participação na rede interorganizacional (WALKER, KOGUT e SHAN, 1997). ${ }^{4}$

Portanto, salvo algumas exceções, ${ }^{5}$ o fato das organizações estarem participando de uma rede e terem ligações com outras organizações, traz ganhos superiores do que os obtidos quando operam de forma isolada. Resta ao pesquisador entender se esses ganhos de sinergia estão relacionados à complementação das atividades e de recursos da organização - geralmente, outros elos da cadeia de valores (DYER e SINGH, 1998) -, ou ao fortalecimento da rede, ou seja, no aumento do poder de barganha das organizações (Ibidem). Por exemplo, numa cooperativa entre diferentes organizações, essa união pode fortalecê-las, principalmente, as que tenham maior poder de negociação e barganha. No caso de uma relação entre fornecedor e fabricante, empresas público-privadas ou uniões empresa-universidade, a aliança gera uma complementariedade das especialidades entre as organizações.

\section{Síntese da categorização das redes interorganizacionais}

O quadro a seguir sintetiza as categorizações propostas para identificação da rede interorganizacional:

\footnotetext{
${ }^{4}$ Para o levantamento de um conjunto abrangente de ganhos provenientes das organizações participantes de redes, ver Carneiro da Cunha (2006).

${ }^{5}$ Por exemplo, Gulati, Nohria e Zaheer (2000) alegam que pode haver organizações com maior poder de barganha atuando sozinhas do que participando de uma rede.
} 
Quadro 1

Síntese das categorizações das redes interorganizacionais

\begin{tabular}{|c|c|}
\hline Item a ser analisado pelo pesquisador & Possibilidades de categoria \\
\hline \multirow{2}{*}{ Formação } & Natural \\
\hline & Induzida \\
\hline \multirow{2}{*}{ Tipo de alianças } & Horizontal \\
\hline & Vertical \\
\hline \multirow{2}{*}{ Orientação das relações } & Fins comerciais (competitividade) \\
\hline & Fins sociais \\
\hline \multirow{2}{*}{ Orientação do elo da cadeia } & Production-driven (produção) \\
\hline & Buyer-driven (comprador) \\
\hline \multirow{2}{*}{ Presença de uma organização central } & Estimulante e fortalecedor \\
\hline & Concorrente \\
\hline \multirow{3}{*}{ Governança } & Sem formalização institucional \\
\hline & Presença de um agente intermediário \\
\hline & Coordenação por uma organização central \\
\hline \multirow{2}{*}{ Institucionalização } & Formal (contratual) \\
\hline & Informal \\
\hline \multirow[b]{2}{*}{ Unidade de análise } & Atores / grupo de atores \\
\hline & $\begin{array}{l}\text { Relacionamentos / grupo de } \\
\text { relacionamentos }\end{array}$ \\
\hline \multirow{2}{*}{ Tipo de competição } & Entre organizações \\
\hline & Entre redes \\
\hline
\end{tabular}




\begin{tabular}{|l|l|}
\hline \multirow{2}{*}{ Proximidade } & Geográfica \\
\cline { 2 - 2 } & Organizacional \\
\cline { 2 - 2 } & Tecnológica \\
\hline \multirow{2}{*}{ Necessidades e sinergias das alianças } & Complementação \\
\cline { 2 - 2 } & Fortalecimento \\
\hline
\end{tabular}

Fonte: Elaborado pelos autores.

É importante deixar claro que a complexidade das categorizações - pode envolver categorias de difícil classificação, mistas ou gradativas, sem que as variáveis sejam dicotômicas. O recomendável é que o pesquisador possa limitar sua rede ou que utilize ferramentas que lhe possibilitem entender o grau de cada categoria, para evitar mal-entendidos.

\section{Discussões finais}

$\mathrm{Na}$ discussão aqui levantada foram feitas algumas recomendações quanto a elementos tidos como importantes para os que pesquisam redes interorganizacionais. Trata-se de apontamentos que os autores deste artigo julgam relevantes e a serem considerados nos estudos sobre o tema.

A primeira recomendação é a de que o pesquisador tenha claros seu objetivo de pesquisa e a epistemologia adotada, antes de ir a campo compreender os fenômenos de uma rede interorganizacional. Isso não apenas ajuda a compreender os resultados levantados sobre seu objeto de pesquisa, como também dá orientações sobre qual tipo de abordagem a ser adotado no acesso ao objeto.

No que tange à orientação epistemológica, é importante deixar claro que o foco deste estudo foi apenas realizar um levantamento de alguns elementos categóricos apontados como relevantes para se identificar a tipologia das redes interorganizacionais quando da realização da pesquisa. Não foram abordadas aqui as linhas de pensamento e epistemologias que podem ser utilizadas para a análise de redes; considerações de suma importância que, no entanto, estão sob outro escopo de análise.

Assim, destaca-se como passo importante para o pesquisador, fazer um levantamento das perspectivas teóricas e epistemológicas que podem guiar seus estudos. Para essa finalidade, já existem pesquisas que abordam essas perspectivas, com destaque para: (1) Borgatti e Foster (2003), que definiram quatro tipos canônicos de estudos sobre redes (capital estrutural, formação ambiental, acesso social aos recursos e difusão); (2) Oliver e Ebers (1998), que identificaram quatro grandes perspectivas para o estudo de redes (redes sociais, poder e controle, institucionalismo, economia institucional e estratégia de clusters); (3) Balestrin e Vargas (2004), que se apoiaram nos autores anteriores para apresentar sete correntes teóricas (economia industrial, estratégias interorganizacionais, dependências de recursos, redes sociais, custos de transações, teoria institucional, teorias críticas e radicais); e (4) Barringer e Harrison (2000), que demonstraram haver seis tipos de explanações teóricas para as relações interorganizacionais (economia dos custos de transação, dependências de recursos, escolhas estratégicas, teoria da firma do stakeholder, 
aprendizagem organizacional e teoria institucional). O importante é que se utilizem teorias adequadas ao objetivo de pesquisa proposto pelo pesquisador (CUNHA e CARRIERI, 2003).

Em uma segunda etapa, com sua orientação epistemológica definida, o pesquisador pode então delimitar seu objeto de estudo, destacando exatamente qual o escopo e os limites da rede que está estudando. Isso facilita a condução da pesquisa e demonstra com clareza até onde vão as considerações do estudo. Posteriormente, o pesquisador tem condições de estabelecer a estratégia de seu estudo, que deve ser capaz atender as suas demandas de pesquisa, conforme o objetivo estabelecido.

Com a estratégia de pesquisa definida, o pesquisador tem maior embasamento para realizar sua pesquisa de campo. Essa abordagem empírica deve sempre ocorrer de forma ética, até mesmo para favorecer os estudos futuros do pesquisador. É importante que se identifique também quem são os informantes-chave (pontos focais) que podem oferecer as informações necessárias para o pesquisador.

Outra dica importante para o pesquisador é analisar o contexto histórico-social no qual a rede está inserida. Essa compreensão pode oferecer informações referentes ao desenvolvimento, à formação e ao encerramento das alianças e da rede. No mais, entender a imersão social da rede pode trazer informações importantes sobre a própria operacionalização, tendências e objetivos da rede.

Depois disso, é possível que o pesquisador identifique e estabeleça o tipo de rede com a qual ele está lidando. Assim, recomenda-se que ele se baseie nos elementos presentes no quadro 1 para realizar essa identificação, porque estas são variáveis que podem categorizar a rede estudada. No entanto, cabe aqui ressaltar que não se pretende que esta discussão contribua com sugestões prescritivas e impositivas sobre a pesquisa da área. Deve ficar claro que não está sendo sugerido aos pesquisadores atuarem dentro de um formato de pesquisa predeterminado e limitante, mas sim que exista uma possível proposta para as escolhas metodológicas e categóricas. É importante que o pesquisador tenha em mente que ele pode acrescentar novas categorias (o que é recomendável), caso ele julgue esse complemento relevante para sua pesquisa.

A partir de uma categorização, o pesquisador pode não apenas compreender melhor a rede que está estudando, mas pode também, a partir dessa compreensão, tecer resultados mais consistentes e compreensíveis em relação à realidade observada. Além do mais, feita essa categorização, o pesquisador pode oferecer resultados específicos mais bem aplicáveis ao(s) tipo(s) de rede(s) que abordou. Não obstante, quando existem categorias definidas, é possível efetuar estudos comparativos entre os resultados obtidos com as pesquisas de campo sobre redes interorganizacionais. Pode-se realizar uma análise peer to peer entre redes ou ainda identificar especificidades de variáveis que variam conforme o tipo de rede com a qual o pesquisador se depara. Isso favorece o avanço do campo de estudo e a construção de conhecimentos, dado que os diferentes estudos poderão melhor relacionados.

Vale ressaltar que, quanto à imersão do pesquisador no campo, os processos de levantamento histórico-social e de categorização podem ser feitos a priori, o que facilita, inclusive, uma posterior escolha estratégica e o acesso a campo mais adequado às características da rede. O problema é que nem sempre o pesquisador consegue identificar essas características antes da parte empírica de seu estudo. Muitas das informações necessárias à caracterização da rede dependem de sua imersão e conhecimento a respeito desta, que ele só teria no momento em que estivesse em contato com a pesquisa de campo. Por isso, nesse racional, sugere-se essa etapa de pesquisa como uma das últimas.

Por fim, é importante que o pesquisador deixe claro no seu relatório de pesquisa quais foram suas escolhas de conceituações, objetivo e objeto de pesquisa, qual o contexto histórico-social desse objeto, a categorização desse objeto, qual a estratégia de pesquisa e a epistemologia adotada. Essa preocupação em facilitar a identificação desses elementos ao longo do texto elaborado auxilia na identificação do tipo de pesquisa e do objeto de estudo abordado, além de ajudar o leitor a compreender os pontos-chave do estudo. 
Isso facilita a recuperação de informações relevantes sobre o objeto e possibilita maior associação e comparação dos estudos da área, tal como, para a construção do conhecimento da mesma.

O quadro a seguir sintetiza a sugestão de passos propostos ao longo deste estudo. Trata-se de uma alternativa aqui recomendada, que os pesquisadores podem seguir nas suas pesquisas sobre redes interorganizacionais.

\section{Quadro 2}

Proposta de ações a serem tomadas pelo pesquisador nos estudos sobre redes interorganizacionais

\begin{tabular}{|c|l|}
\hline Passos & \multicolumn{1}{c|}{ Ações do pesquisador } \\
\hline 1 & Estabelecer a epistemologia e o objetivo de pesquisa \\
\hline 2 & Limitar a rede conforme os objetivos da pesquisa \\
\hline 3 & $\begin{array}{l}\text { Escolher a estratégia de pesquisa mais adequada aos objetivos de estudo, para que } \\
\text { fundamentem suas definições conceituais e a coleta de dados }\end{array}$ \\
\hline 4 & $\begin{array}{l}\text { Atentar para seus pontos focais na pesquisa empírica e realizar seu estudo pautado por } \\
\text { padrões éticos }\end{array}$ \\
\hline 5 & Compreender o contexto histórico-social da rede \\
\hline 6 & Categorizar a rede \\
\hline 7 & $\begin{array}{l}\text { Deixar claro no relatório final de pesquisa as categorizações do seu objeto de estudo e as } \\
\text { justificativas de suas escolhas metodológicas }\end{array}$ \\
\hline
\end{tabular}

Fonte: Elaborado pelos autores.

Um ponto importante, que deve ficar claro para evitar mal-entendidos, é que este estudo não tem a pretensão de auxiliar na prática de gestão das redes interorganizacionais, mas, sobretudo, auxiliar na prática de pesquisas sobre essas formas organizacionais. Portanto, esse artigo tem como público-alvo os pesquisadores da área e não os gestores de redes.

\section{Limitações Deste Estudo e Sugestões para Estudos Futuros}

Este estudo se concentrou na preparação da pesquisa de campo e na documentação desta pesquisa. Não focou em como oferecer um conjunto completo de recomendações sobre a operacionalização das pesquisas de campo. Um estudo futuro poderia complementar este levantamento, apresentando recomendações sobre como realizar operacionalmente uma pesquisa de campo sobre redes interorganizacionais. 
Da mesma forma, as atuais recomendações limitam-se à perspectiva teórica. Por isso, sugere-se que futuros estudos sejam direcionados à identificação de casos empíricos das categorias de redes apresentadas, visando a um acúmulo de conhecimentos específicos sobre cada tipo de rede interorganizacional. Isso pode facilitar o desenvolvimento do campo com estudos comparativos e com a maior facilidade de se acumular conhecimentos sobre os tipos de redes. Dessa forma, pode-se estabelecer também uma relação entre teoria e prática capaz não apenas de oferecer subsídios validados para pesquisas acadêmicas sobre o tema, mas também de possibilitar uma compreensão empírica sobre fenômenos ocorridos nas redes interorganizacionais.

No mais a interação bidimensional entre duas diferentes categorias pode, em si, gerar para as redes, subcategorias que auxiliariam alguns pesquisadores da área a entender mais profundamente algumas especificidades de seus estudos. Portanto, inter-relacionar as categorias aqui citadas pode ser uma forma de avançar ainda nas possíveis categorizações sobre redes interorganizacionais.

\section{Referências}

AGRANOFF, R.; McGUIRE, M. Managing in network settings. Review of Policy Research, v.16, n.1, p.18-41, 1999.

ALVES, J. N.; PEREIRA, B. A. D.; BAZZO, P. S. Confiança, conhecimento e aprendizagem nos relacionamentos interorganizacionais: diagnóstico $\mathrm{e}$ análise dos avanços sobre o tema. In: ENCONTRO DE ESTUDOS ORGANIZACIONAIS - ENEO, 6., 2010, Florianópolis. Anais... Belo Horizonte: ANPAD, 2010.

ARIÑO, A.; DE LA TORRE, J. Learning from failure: towards an evolutionary model of collaborative ventures. Organization Science, v.9, n.3, p.306-325, 1998.

AUSTIN, J.; STEVENSON, H.; WEI-SKILLERN, J. Social and commercial entrepreneurship: same, different or both? Entrepreneurship Theory and Practice, v.30, n.1, p.1-22, 2006.

BALDI, M.; VIEIRA, M. M. F. Calçado do Vale: imersão social e redes interorganizacionais. RAE - Revista de Administração de Empresas, v.46, n.3, p.16-27, 2006.

BALESTRIN, A.; VARGAS, L. M. A Dimensão estratégica das redes horizontais de PMEs: teorizações e evidências. RAC - Revista de Administração Contemporânea, Edição Especial, p.203-227, 2004.

BALESTRIN, A; VERSCHOORE, J. R.; REYES JUNIOR, E. O campo de estudo sobre redes de cooperação interorganizacional no Brasil. RAC - Revista de Administração Contemporânea, v.14, n.3, p.458-477, 2010.

BARRINGER, B. R.; HARRISON, J. S. Walking a tightrope: creating value through interorganizational relationships. Journal of Management, v.26, n.3, p.367-403, 2000.

BEGNIS, H. S. M.; PEDROZO, E. A.; ESTIVALETE, V. F. B. Cooperação enquanto estratégia, segundo diferentes perspectivas teóricas. In: ENCONTRO DA ASSOCIAÇÃO NACIONAL DE PÓS-GRADUAÇÃO E PESQUISA EM ADMINISTRAÇÃO - ENANPAD, 29., 2005, Brasília, DF. Anais... Belo Horizonte: ANPAD, 2005.

BENGSTON, M.; KOCK, S. "Coopetition" in business networks - to cooperate and compete simultaneously. Industrial Marketing Management, v.29, n.5, p.411-426, 2000.

BORGATTI, S. P.; FOSTER, P. C. The network paradigm in organizational research: a review and typology. Journal of Management, v.29, n.6, p.991-1013, 2003.

BORGATTI, S. P.; MOLINA, J. L. Ethical and strategic issues in organizational social networks analysis. Journal of Applied Behavioral Science, v.39, n.3, p.337-349, 2003. 
BRASS, D. J. et al. Taking stock of networks and organizations: a multilevel perspective. Academy of Management Journal, v.47, n.6, p.795-817, 2004.

CANINA, L.; ENZ, C. A.; HARRISON, J. S. Agglomeration effects and strategic orientations: evidence from the U.S. lodging industry. Academy of Management Journal, v.48, n.4, p.565-581, 2005.

CARNEIRO DA CUNHA, J. A. O processo de transmissão de conhecimentos em redes interorganizacionais: a experiência do arranjo produtivo local de Birigüi (SP). Dissertação (Mestrado em Administração de Organizações) Faculdade de Economia, Administração e Contabilidade de Ribeirão Preto, Universidade de São Paulo, Ribeirão Preto, 2006.

Sobre arranjos produtivos locais e clusters. In: ENCONTRO DE ADMINISTRAÇÃO PÚBLICA E GOVERNANÇA - ENAPG, 3., 2008, Salvador. Anais... Belo Horizonte: ANPAD, 2008.

CASTELLS, M. A sociedade em rede. 8.ed. São Paulo: Paz e Terra, 1999.

CHESBROUGH, H.; ROSENBLOOM, R. S. The role of the business model in capturing value from innovation: evidence from Xerox Corporation's technology spin-off companies. Industrial and Corporate Change, v.11, n.3, p.529-555, 2002.

CONTRACTOR, F. J.; LORANGE, P. The growth of alliances in the knowledge-based economy. International Business Review, v.11, n.4, p.485-502, 2002.

COOPER, H. M. Synthesizing research: a guide for literature reviews. 3.ed. Thousand Oaks: Sage, 1998.

CORRÊA, G. N. Proposta de otimização da integração de parceiros na formação e gerência de empresas virtuais. Tese (Doutorado em Engenharia Mecânica) - Escola de Engenharia de São Carlos, Universidade de São Paulo, São Carlos, 1999.

COZER, M. T. S.; PÓLO, E. F.; CAMPOMAR, M. C. Information based metaphors: from brain to network. Journal of Information Systems \& Technology Management, v.6, n.2, p.271-290, 2009.

CUNHA, C. R.; CARRIERI, A. P. Mapeando as relações interorganizacionais na teoria organizacional: garimpando os principais periódicos brasileiros sobre gestão. In: ENCONTRO DA ASSOCIAÇÃO NACIONAL DE PÓSGRADUAÇÃO E PESQUISA EM ADMINISTRAÇÃO - ENANPAD, 27., 2003, Atibaia, SP. Anais... Belo Horizonte: ANPAD, 2003.

DACIN, M. T.; HITT, M. A.; LEVITAS, E. Selecting partners for successful international alliances. Journal of World Business, v.32, n.1, p.321-345, 1997.

DAS, T. K.; TENG, B. Alliance constellations: a social exchange perspective. Academy of Management Review, v.27, n.3, p.445-456, 2002.

DIMAGGIO, P. J.; POWELL, W. W. The Iron Cage revisited: institutional isomorphism and collective rationality in organizational fields. American Sociological Review, v.48, n.2, p.147-160, 1983.

DOZ, Y. L.; HAMEL, G. A. Vantagem competitiva das alianças: a arte de criar valor através de parcerias. Rio de Janeiro: Qualitymark, 2000.

DYER, J. H. Effective interfirm collaboration: how firms minimize transaction costs and maximize transaction value. Strategic Management Journal, v.18, n.7, p.553-556, 1997.

DYER, J. H.; SINGH, H. The relational view: cooperative strategy and sources of interorganizational competitive advantage. Academy of Management Review, v.23, n.4, p.660-679, 1998. 
EVAN, W. M. Toward a theory of inter-organizational relations. Management Science, v.11, n.10, p.B217-B230, 1965.

FOMBRUN, C. J. Strategies for network research in organizations. Academy of Management Review, v.7, n.2, p.280291, 1982.

FORREST, J. B. Networks in the policy process: an international perspective. International Journal of Public Administration, v.26, n.6, p.591-607, 2003.

GAJDA, R. Utilizing collaboration theory to evaluate strategic alliances. American Journal of Evaluation, v.25, n.1, p.65-77, 2004.

GEREFFI, G. International trade and industrial upgrading in the apparel commodity chain. Journal of International Economics, v.48, n.1, p.37-70, 1999.

GHOSHAL, S. Bad management theories are destroying good management practices. Academy of Management Learning \& Education, v.4, n.1, p.75-91, 2005.

GOMES-CASSERES, B. Group versus group: how alliances networks compete. Harvard Business Review, v.72, n.7/8, p.62-74, 1994.

. Alliance strategies of small firms. Small Business Economics, v.9, n.1, p.33-44, 1997.

GRANDORI, A.; SODA, G. Inter-firms network: antecedents, mechanisms and forms. Organization Studies, v.16, n.2, p.183-214, 1995.

GRANOVETTER, M. The strength of weak ties. American Journal of Sociology, v.78, n.6, p.1360-1380, 1973.

Economic action and social structure: the problem of embeddedness. American Journal of Sociology, v.91, n.3, p.481-510, 1985 .

GRANT, R. M. Toward a knowledge-based theory of the firm. Strategic Management Journal, v.17, Special Issue, p.109-122, 1996.

GULATI, R. Social structure and alliance formation patterns: a longitudinal analysis. Administrative Science Quarterly, v.40, n.4, p.619-652, 1995.

Alliances and networks. Strategic Management Journal, v.19, n.4, p.293-317, 1998.

.; NOHRIA, N.; ZAHEER, A. Strategic networks. Strategic Management Journal, v.21, n.3, p.203-215, 2000.

HALINEN, A.; TÖRNROOS, J. The role of embeddedness in the evolution of business networks. Scandinavian Journal of Management, v.14, n.3, p.187-205, 1998.

Using case methods in the study of contemporary business networks. Journal of Business Research, v.58, n.9, p.1285-1297, 2005.

HARRIGAN, K. R. Strategic alliances and partner asymmetries. In: CONTRACTOR, F. J.; LORANGE, P. (Orgs.). Cooperative Strategies in International Business. Lexington: Lexington Books, 1988.

HASTENREITER FILHO, H. N. Acertos e desacertos dos principais programas de redes de cooperação interempresariais brasileiros. In: TEIXEIRA, F. (Org.). Gestão de redes de cooperação interempresariais: em busca de novos espaços para o aprendizado e a inovação. Salvador: Casa da Qualidade, 2005.

HEDAA, L.; TÖRNROOS, J. Understanding event-based business networks. Time \& Society, v.17, n.2/3, p.319-348, 2008. 
HOLLOWAY, S. S. When does the network organizational form fail? Examining the impact of project characteristics on organizational structures and performance. Tese (Doutorado em Administração) - Department of Management, University of Oregon: Eugene, 2009.

INOJOSA, R. M. Redes de compromisso social. RAP - Revista de Administração Pública, v.33, n.5, p.115-141, 1999.

JARILLO, J. C. On strategic networks. Strategic Management Journal, v.9, n.1, p.31-41, 1988.

JONES, C.; HESTERLY, W. S.; BORGATTI, S. P. A general theory of network governance: exchange conditions and social mechanisms. Academy of Management Review, v.22, n.4, p.911-945, 1997.

KNOBEN, J.; OERLEMANS, L. A. G. Proximity and inter-organizational collaboration: a literature review. International Journal of Management Reviews, v.8, n.2, p.71-89, 2006.

KUMAR, N.; STERN, L. W.; ANDERSON, J. C. Conducting interorganizational research using key informants. Academy of Management Journal, v.36, n.6, p.1633-1651, 1993.

LAUMANN, E. O.; PAPPI, F. U. Networks of collective action. New York: Academic Press, 1976.

LORANGE, P.; ROOS, J. Alianças estratégicas: formação, implementação e evolução. São Paulo: Atlas, 1996.

MARSDEN, P. V. Recent developments in network measurement. In: CARRINGTON, P. J.; SCOTT, J.; WASSERMAN, S. (Orgs.). Models and methods in social network analysis. New York: Cambridge University Press, 2005.

MARTELETO, R. M.; SILVA, A. B. O. Redes e capital social: o enfoque da informação para o desenvolvimento local. Ciência da Informação, v.33, n.3, p.41-49, 2004.

MAXWELL, J. A. Qualitative research design: an interactive approach. $2^{\text {nd }}$ ed. Thousand Oaks: Sage, 2005.

MESQUITA, L. F.; LAZZARINI, S. G. Horizontal and vertical relationships in developing economies: implications for SMEs' access to global markets. Academy of Management Journal, v.51, n.2, p.359-380, 2008.

MILES, R. E.; SNOW, C. C. Causes of failure in network organizations. California Management Review, v.34, n.4, p.53-72, 1992.

MORGAN, G. Research strategies: Modes of engagement. In: MORGAN, G. (Org.). Beyond method: strategies for social research. London; Sage, 1983.

NARAYAN, D. Bonds and bridges: social capital and poverty. In: ISHAM, J.; KELLY, T.; RAMASWAMY, S. (Orgs.). Social capital and economic development: well-being in developing countries. Cheltenham: Edgar Elgar, 2002.

NIELSEN, B. The hole of knowledge embeddedness in the creation of synergies in strategic alliances. Journal of Business Research, v.58, n.9, p.1194-1204, 2005.

NOHRIA, N. Is a network perspective a useful way of studying organizations? In: NOHRIA, N.; ECCLES, R. G. (Orgs.). Networks and organizations: structure, form and action. Boston: Harvard Business School Press, 1992.

OLIVER, A. L.; EBERS, M. Networking network studies: an analysis of conceptual configurations in the study of interorganizational relationships. Organization Studies, v.19, n.4, p.549-583, 1998.

OLIVER, C. Determinants of interorganizational relationships: integrations and future directions. Academy of Management Review, v.15, n.2, p.241-265, 1990. 
ORDANINI, A.; RUBERA, G.; DEFILLIPPI, R. The many moods of inter-organizational imitation: a critical review. International Journal of Management Reviews, v.10, n.4, p.375-398, 2008.

OWEN-SMITH, J.; POWELL, W. W. Knowledge networks as channels and conduits: the effects of spillovers in the Boston biotechnology community. Organization Science, v.15, n.1, p.5-21, 2004.

PARK, S. H. Managing an interorganizational network: a framework of the institutional mechanism for network control. Organization Studies, v.17, n.5, p.795-824, 1996.

PASSADOR, J. L. Política pública em ciência e tecnologia: as redes de fomento tecnológico e as relações entre governo, empresa e universidade. In: CONGRESSO INTERNACIONAL DEL CLAD, 8., 2003, Ciudad de Panamá, Panamá. Anais... Caracas: CLAD, 2003.

PASSADOR, J. L.; CARNEIRO DA CUNHA, J. A. A formação de alianças e redes interorganizacionais. In: C. S. PASSADOR, C. S.; PASSADOR, J. L. (Orgs.). Gestão pública e desenvolvimento no século XXI: casos da Companhia de Desenvolvimento dos Vales São Francisco e do Parnaíba (Codevasf). São Paulo: Annablume, 2008.

PHAM, S. Inter-firms network literatures: a review and critique. Copenhagen Business School working paper: Copenhagen (Dinamarca): s/d. Disponível em: <http://www.cbs.dk/content/download/47338/686214/file/Pham.doc>. Acesso em: 1 jun. 2010.

PODOLNY, J. M.; PAGE, K. L. Network forms of organization. Annual Review of Sociology, v.24, p.57-76, 1998.

PORTER, M. E. Clusters and the new economics of competition. Harvard Business Review, v.76, n.6, p.77-90, 1998.

POWELL, W. W. Hybrid organizational arrangements: new form or transitional development? California Management Review, v.30, n.1, p.67-87, 1987.

Neither market nor hierarchy: networks forms of organization. In: STRAW, B. M.; CUMMINGS, L. L. (Orgs.). Research in organizational behavior. Greenwich: JAI Press, 1990.

et al. Network dynamics and field evolution: the growth of interorganizational collaboration in the life sciences.

American Journal of Sociology, v.110, n.4, p.1132-1205, 2005.

; GRODAL, S. Networks of innovators. In: FAGEBERG, J.; MOWERY, D. C.; NELSON, R. R. (Orgs.). The Oxford handbook of innovation. Oxford: Oxford University Press, 2005.

PRAHALAD, C. K.; RAMASWAMY, V. O futuro da competição: como desenvolver diferenciais inovadores em parcerias com clientes. Rio de Janeiro: Campus, 2004.

PRENKERT, F.; HALLÉN, L. Conceptualising, delineating and analysing business networks. European Journal of Marketing, v.40, n.3/4, p.384-407, 2006.

PROVAN, K. G.; FISH, A.; SYDOW, J. Interorganizational networks at the network level: a review of the empirical literature on whole networks. Journal of Management, v.33, n.3, p.479-516, 2007.

PROVAN, K. G.; KENIS, P. Modes of network governance: structure, management, and effectiveness. Journal of Public Administration Research and Theory, v.18, n.2, p.229-257, 2008.

RING, P. S.; VAN DE VEN, A. H. Developmental processes of cooperative interorganizational relationships. Academy of Management Review, v.19, n.1, p.90-118, 1994.

RITTER, T.; GEMÜNDEN, H. G. Interorganizational relationships and networks: an overview. Journal of Business Research, v.56, n.9, p.691-697, 2003. 
ROWLEY, T. J. Moving beyond dyadic ties: a network theory of stakeholder influences. Academy of Management Review, v.22, n.4, p.887-910, 1997.

SALANCIK, G. R. Wanted: a good network theory of organization. Administrative Science Quarterly, v.40, n.2, p.345-349, 1995.

SILVERMAN, B. S.; BAUM, J. A. C. Alliance-based competitive dynamics. Academy of Management Journal, v.45, n.4, p.791-806, 2002.

SIMMEL, G. Conflict and the Web of group affiliations. New York: Free Press, 1955.

SMITH, K. G.; CARROLL, S. J.; ASHFORD, S. J. Intra and interorganizational cooperation: toward a research agenda. Academy of Management Journal, v.38, n.1, p.7-23, 1995.

SMITH-DOER, L.; POWELL, W. W. Networks and economic life. In: SMELSER, N. J.; SWEDBERG, R. (Orgs.). The Handbook of Economic Sociology. $2^{\text {nd }}$ ed. Princeton: Princeton University Press, 2004.

STRAUSS, A. L. Qualitative analysis for social scientists. Cambridge: Cambridge University Press, 1987.

SYDOW, J.; WINDELER, A. Organizing and evaluating interfirm networks: a structurationist perspective on network processes and effectiveness. Organization Science, v.9, n.3, p.265-284, 1998.

TAYLOR, A. An operations perspective on strategic alliances success factors: an exploratory study of alliance managers in the software industry. International Journal of Operations \& Production Management, v.25, n.5, p.469-490, 2005.

TELLES, L. O. Clusters e a indústria ligada à área da saúde em Ribeirão Preto. Dissertação (Mestrado em Economia) - Faculdade de Economia, Administração e Contabilidade, Universidade de São Paulo, São Paulo, 2002.

THORELLI, H. B. Networks: between markets and hierarchies. Strategic Management Journal, v.7, n.1, p.37-51, 1986.

TODEVA, E. Business networks in China: legacies and practice. In: CLEGG, S.; WANG, K.; BERRELL, M. (Orgs.). Business networks and strategic alliances in China. Cheltenham: Edward Elgar, 2007.

TODEVA, E.; KNOKE, D. Strategic alliances and models of collaboration. Management Decision, v.43, n.1, p.123148, 2005.

TÖRNROOS, J. Terminating relationships in business networks? Reflections on business strategies. In: $20^{\text {th }}$ ANNUAL CONFERENCE OF THE INDUSTRIAL MARKETING AND PURCHASING (IMP) GROUP, Copenhagen, Denmark, 2004. Anais...

TORRE, A.; RALlET, A. Proximity and localization. Regional Studies, v.39, n.1, p.47-59, 2005.

UZZI, B. Social structure and competition in interfirm networks: the paradox of embeddedness. Administrative Science Quarterly, v.42, n.1, p.35-67, 1997.

VIZEU, F. Pesquisas sobre redes interorganizacionais: uma proposta de distinção paradigmática. In: ENCONTRO DA ASSOCIAÇÃO NACIONAL DE PÓS-GRADUAÇÃO E PESQUISA EM ADMINISTRAÇÃO - ENANPAD, 27. 2003, Atibaia, SP. Anais... Belo Horizonte: ANPAD, 2003.

VLAAR, P. W. L.; VAN DEN BOSCH, F. A. J.; VOLBERDA, H. W. Towards a dialectic perspective on formalization in interorganizational relationships: how alliance managers capitalize on the duality inherent in contracts, rules and procedures. Organization Studies, v.28, n.4, p.437-466, 2007. 
WALKER, G.; KOGUT, B.; SHAN, W. Social capital, structural holes and the formation of an industry network. Organization Science, v.8, n.2, p.109-125, 1997.

WHETTEN, D. A. Interorganizational relations: a review of the field. Journal of Higher Education, v.52, n.1, p.1-28, 1981.

WILLIAMSON, O. E. Transaction-cost economics: the governance of contractual relations. Journal of Law \& Economics, v.22, n.2, p.233-261, 1979.

WILLIAMS, T. Cooperation by design: structure and cooperation in interorganizational networks. Journal of Business Research, v.58, n.2, p.223-231, 2005.

YEUNG, H. W. Business networks and transnational corporations: a study of Hong Kong firms in the Asian region. Economic Geography, v.73, n.1, p.1-25, 1997.

YOSHINO, M. Y.; RANGAN, U. S. Strategic alliances: an entrepreneurial approach to globalization. Boston: Harvard Business School Publishing, 1995.

ZACCARELLI, S. B. et al. Clusters e redes de negócios: uma nova visão para a gestão dos negócios. São Paulo: Atlas, 2008.

ZAHEER, A.; BELL, G. G. Benefiting from network position: firm capabilities, structural holes, and performance. Strategic Management Journal, v.26, n.9, p.809-825, 2005. 